\title{
Procuramiento y uso de aloinjertos cutáneos de piel total criopreservados obtenidos de pacientes sometidas a abdominoplastía
}

\author{
Marcelo Fonseca C. ${ }^{1}$, Aldo Cañete S. ${ }^{1,2}$, Dino Ibaceta O. ${ }^{1}$, Jennifer Gómez A. ${ }^{2}$, \\ Mónica Santander M. ${ }^{3}$, Paulina Acuña S. ${ }^{4}$, Luana Mandriaza M. ${ }^{5}$, Pamela Vidal N. ${ }^{5}$, \\ Manuel Moya D. ${ }^{1}$, Giovanni Vivas R. ${ }^{1}$, Nicolle Delgado C. ${ }^{1}$, Florencia Disi P. ${ }^{6}$, \\ Paula Vásquez H. ${ }^{6}$, Juan Olivares C. ${ }^{7}$ y Catalina Buchroithner H. ${ }^{8}$
}

Procurement and use of cryopreserved whole skin cutaneous allografts obtained from patients undergoing abdominoplasty

Introduction: Skin allografts (SA) are outstanding temporary skin substitutes; however, cadaveric skin donation and procurement, a common source of SA, remains low. Aim: To evaluate the feasibility and clinical efficacy of using skin from abdominoplasties as a source of SA. Materials and Method: A prospective cohort was analyzed from August 17th, 2020 and February 28th, 2021, with 14 female patients submitted to abdominoplasty surgeries for aesthetic motives, who authorized skin donation from the redundant abdominal flap which was posteriorly cryopreserved. Cryopreserved total skin allografts (CTSA) was used in 10 patients with the following diagnoses: diabetic foot (4), contained laparostomy (2) complex wound of the lower limb (2), relapsing sarcoma of the scalp (1), and melanoma (1). Results: 14 CTSA were obtained, which were processed, obtaining an average area of $302 \mathrm{~cm}^{2}$ and 8.3 sheets of different sizes and clinical applications from each patient. In all patients who received CTSA, an initial attachment was observed, followed by the appearance of a necrotic scar in an average of 21 days. The peeling of the latter revealed a vital tissue tightly adhered to the receptor and rich in fibroblasts. Some of the patients received autografts, and others were managed with secondary intention scarring as a definite treatment. Discussion: CTSA provide an intermediate coverage since one part is definitely adhered to, acting as a biologic scaffolding for the formation of an interface that can be autografted or left for a secondary intention scarring, and the host rejects the other portion. Conclusion: skin procurement from a living donor in patients submitted to body contour surgeries is a feasible process and significant source of CTSA, which permits a new intermediate coverage with multiple clinical uses.

Keywords: skin; abdominoplasty; biological dressings.

\section{Resumen}

Introducción: Los aloinjerto cutáneos (AC) son excelentes sustitutos cutáneos temporales, sin embargo, la donación y procura de piel cadavérica, fuente habitual de AC, es baja. Objetivo: Evaluar la factibilidad de utilizar la piel proveniente de abdominoplastías como fuente de AC y su eficacia clínica. Materiales y Método: Entre el 17 de agosto de 2020 al 28 de febrero de 2021 se analizó una cohorte prospectiva de 14 pacientes femeninas sometidas a abdominoplastía por motivos estéticos, que aceptaron donar la piel del colgajo cutáneo abdominal redundante, la cual fue criopreservada. Se utilizaron los AC de piel total criopreservados (ACPTC) en 10 pacientes con diagnósticos de: pie diabético (4), laparostomía contenida (2) herida compleja extremidad inferior (2), sarcoma de cuero cabelludo recidivado (1) y melanoma (1). Resultados: Se obtuvieron 14 colgajos de piel total, los cuales fueron procesados obteniendo una superficie promedio de $302 \mathrm{~cm}^{2}$ y 8,3 láminas de distintos tamaños de utilidad clínica por paciente. En todos los pacientes en que se utilizó ACPTC hubo un prendimiento inicial del AC para posteriormente, en promedio 21 días, presentar una escara necrótica que al ser retirada presentaba un tejido vital adherido al receptor rico en fibroblastos, siendo algunos pacientes auto injertados y otros manejados con cicatrización 
por segunda intención como tratamiento definitivo. Discusión: Los ACPTC proporcionan una cobertura intermedia, pues una parte se integra en forma definitiva, actuando como un andamiaje biológico para la formación de una interfase sobre la cual se puede autoinjertar o dejar evolucionar con cicatrización por segunda intención y una parte es rechazada. Conclusión: La procura de piel de donante vivo, en pacientes sometidos a cirugías de contorno corporal es un proceso factible, fuente de ACPTC, los cuales permiten una nueva cobertura intermedia con múltiples aplicaciones clínicas.

Palabras clave: piel; abdominoplastía; apósitos biológicos.

Y el mundo se redujo a la superficie de su piel, y el interior quedó a salvo de toda la amargura.

Cien años de soledad. Gabriel García Márquez

\section{Introducción}

El daño cutáneo extenso, producido principalmente en pacientes quemados, pero también en otras situaciones como traumatismos y enfermedades dermatológicas que generan destrucción y desepitelización de vastos segmentos corporales, ha obligado a la búsqueda de coberturas y sustitutos cutáneos, teniendo que destacar que pese a todo el desarrollo tecnológico actual, los injertos cutáneos autólogos continúan siendo el estándar de tratamiento, principalmente porque no existe el riesgo de rechazo, logrando de esta forma una cobertura y solución definitiva. Sin embargo, presentan como desventaja, la morbilidad de la zona dadora y la escasez de las mismas, sobre todo si hay extensas superficies cutáneas afectadas ${ }^{1-5}$.

Los aloinjertos cutáneos (AC), los cuales provienen de individuos de la misma especie, son un excelente sustituto, pues cumplen las mismas funciones de la piel autóloga, no obstante, debido a procesos de inmunidad son rechazados, siendo sólo utilizados como cobertura temporal, pudiendo eventualmente ser vector de enfermedades infectocontagiosas ${ }^{6-10}$. Actualmente, existe un bajo número de donantes y la logística de la procura, procesamiento y almacenamiento de la piel para su uso clínico es compleja; siendo además, según la última norma general técnica para el procuramiento, preservación e implante de tejidos del Ministerio de Salud de Chile (Minsal, febrero de 2018) sólo reservada para donantes cadavéricos, obteniendo de esta forma sólo escasos AC de espesor parcial, con los cuales existe una amplia experiencia clínica en la literatura ${ }^{11-15}$.

Los múltiples beneficios clínicos, pero a su vez la escasez de $\mathrm{AC}$, abren la puerta para la búsqueda de potenciales donantes de piel, particularmente en donantes vivos a los cuales, por su condición de salud, se les debe resecar grandes cantidades de piel para su mejoría clínica, como son aquellos sometidos a una abdominoplastía por motivos estéticos y/o reconstructivos, pudiendo obtener asimismo AC de piel total (ACPT) ${ }^{16,17}$. El objetivo del presente trabajo es evaluar la factibilidad y estandarizar la procura de piel total en pacientes sometidas a abdominoplastía y eventualmente a cualquier cirugía de contorno corporal y evaluar su eficacia clínica.

\section{Materiales y Método}

Desde el 17 de agosto de 2020 al 28 de febrero de 2021, se evaluaron a 14 pacientes que solicitaron, en la consulta privada del primer autor, una abdominoplastía para mejorar el aspecto estético del abdomen, las cuales terminado el proceso de evaluación, exámenes preoperatorios y consentimiento informado para dicha cirugía, se las invitó a participar en la donación de la piel proveniente del colgajo dermograso abdominal resecado. Se verificó la ausencia de criterios de exclusión de donación de tejidos (Tabla 1), se las sometió a una encuesta de salud (Tabla 2) y se tomaron exámenes de laboratorio de rutina de donación de tejidos durante la cirugía, para no tener periodo de ventana (Tabla 3), obteniendo la firma del consentimiento informado de la donación de tejido, siendo ingresadas al sistema integrado de donación de órganos y trasplante (SIDOT). Posterior a la selección del donante, el proceso se dividió en 10 pasos: 1) proceso quirúrgico/abdominoplastía; 2) procura propiamente tal; 3) empaque e identificación; 4) almacenamiento, 5) transporte al centro de procesamiento; 6) procesamiento; 7) criopreservación/cuarentena; 8) validación, liberación, registros; 9) traslado; 10) uso clínico. Todos los procesos siguieron la norma técnica para el procuramiento, preservación e implante de tejidos del Minsal. 
Tabla 1. Criterios de exclusión donación de piel

a. Por enfermedades infecciosas

a. Pacientes con antecedentes o portadores de VIH/SIDA

b. Pacientes con antecedentes de hepatitis B o C

c. Pacientes con antecedentes de TBC activa

d. Pacientes con diagnóstico de sífilis o VDRL positivo

e. Pacientes con diagnóstico de HTLV I y II

f. Pacientes con diagnóstico de Chagas

g. Pacientes con diagnóstico de rabia, rubéola congénita y malaria

h. Pacientes con diagnóstico de endocarditis bacteriana o fúngica no tratada

b. Por enfermedades del SNC

- Enfermedades degenerativas

a. Cualquier tipo o manifestación de demencia

b. Alzheimer

c. Parkinson

d. Esclerosis múltiple

e. Creutzfeld Jakob

- Enfermedades infecciosas

a. Encefalitis bacteriana

b. Meningitis viral, fúngica o parasitaria

c. Meningitis bacteriana

d. Leucoencefalopatía multifocal progresiva

e. Panencefalitis esclerosante subaguda

f. Encefalitis viral activa o encefalitis de causa desconocida

g. Encefalitis fúngica o parasitaria

c. Por presencia $\mathrm{Ca}$ y/o tumores

a. Historia de neoplasia excepto cáncer cérvico uterino in situ

b. Linfadenopatías con más de un mes de duración

c. Linfomas, linfosarcomas

d. Leucemias

e. Metástasis de tumores malignos primarios o secundarios. (pulmón, mama, cervicouterino, colon, próstata, células escamosas, melanomas, linfomas, leucemias, sistema nervioso central, entre otros)

d. Por otras patologías

- Pacientes que hayan sido tratados con hormona del crecimiento

- Pacientes portadores de hemofilia

- Pacientes portadores de enfermedades autoinmunes o mesenquimopatías como artritis reumatoide, lupus eritematoso sistémico

- Pacientes que hayan sido tratados con una terapia prolongada con corticoides

- Pacientes con quemaduras de más de un 20\% en SCQ en etapa aguda

- Cualquier alteración cutánea sospechosa

- Causa desconocida de muerte

e. Por comportamiento:

- Conducta sexual de riesgo

- Drogadicción endovenosa (incluye intravenosa, intramuscular y subcutánea)

- Personas que ejercen comercio sexual

- Reclusos

- Individuos con tatuajes, piercing corporales realizados en los últimos 6 meses

- Individuos de los cuales no se pueda recopilar antecedentes de comportamiento sexual

f. Por criterios específicos para piel

- Piel contaminada por tóxicos

- Piodermitis

- Cualquier lesión cutánea: infecciosa, traumática o vascular

- Psoriasis

- Epidermólisis bulosa

- Loxocelismo

- Causa de muerte por envenenamiento con tóxicos sistémicos

- Piel estructuralmente dañada (por enfermedades autoinmunes o del colágeno) 
Tabla 2. Cuestionario donante vivo de tejidos

¿Se siente bien de salud el día de hoy?

¿Goza, en general, de buena salud?

¿Durmió al menos 5 horas?

¿Ha bebido alcohol las últimas 12 horas?

¿Ha donado sangre en el último año?

¿Algún profesional de salud le ha dicho que no puede donar sangre?

¿Ha acudido a otra consulta médica en los últimos 6 meses?

¿Se ha realizado algún procedimiento dental en la última semana?

¿En los últimos 6 meses ha sido hospitalizado u operado?

¿Ha recibido alguna transfusión en los últimos 12 meses?

¿En los últimos 12 meses se ha tomado exámenes de sangre?

¿Tiene o ha tenido alguna enfermedad al corazón, pulmón, riñones, tiroides, hipertensión arterial, diabetes mellitus, tendencia a sangrar u otra?

¿Ud. toma algún medicamento en forma habitual en los últimos 6 meses?

¿Ha tomado aspirina o antiinflamatorios en los últimos 3 días?

¿En los últimos 4 días se ha puesto alguna inyección o vacuna?

¿Ha tenido un cuadro de diarrea los últimos 7 días?

¿Ha tenido cáncer alguna vez?

¿Tiene antecedentes de epilepsia, convulsiones o desmayos?

¿Tiene o ha tenido hepatitis o se ha puesto amarillo?

¿Ha recibido algún trasplante o injerto de tejido?

¿Ha recibido tratamiento con hormona del crecimiento antes de 1985 ?

¿Tiene historia familiar de Creutzfeldt-Jakob?

¿Tiene Ud. o su familia antecedentes de demencia, Alzheimer, Parkinson, esclerosis múltiple u otra enfermedad degenerativa?

¿Tiene usted o su familia antecedentes de enfermedad de Chagas?

¿Ha tenido malaria, dengue o fiebre inexplicable durante o después de un viaje fuera del país?

¿Ha viajado fuera del país los últimos 3 años?, ¿donde?

¿En los últimos 6 meses se ha realizado algún tatuaje, piercing, acupuntura o ha sufrido algún pinchazo accidental con aguja o jeringa con sangre?

¿Ha probado algún tipo de droga como marihuana, cocaína, pasta base u otro?, ¿cuáles y cuándo?

¿Ha usado drogas ilegales inyectables o inhalatorias en los últimos 12 meses?

¿Ha tenido relaciones sexuales con alguien que alguna vez se ha inyectado drogas?

¿Ha tenido enfermedades de transmisión sexual como sífilis, gonorrea u otra, en los últimos 12 meses?

¿Ha tenido más de una pareja sexual en los últimos 12 meses?

¿Ha tenido relaciones sexuales con una pareja nueva en los últimos 6 meses?

¿Ha tenido contacto sexual con personas con hepatitis, VIH o HTLV en los últimos 12 meses?

¿Ha pagado o recibido dinero, droga u otro elemento por tener relaciones sexuales en los últimos 12 meses?

¿Cree haberse expuesto al riesgo de infectarse con el virus del SIDA?

¿Está donando tejidos para que pueda hacerse el test del SIDA?

¿Le han ofrecido dinero por donar su tejido? 


\section{Tabla 3. Exámenes}

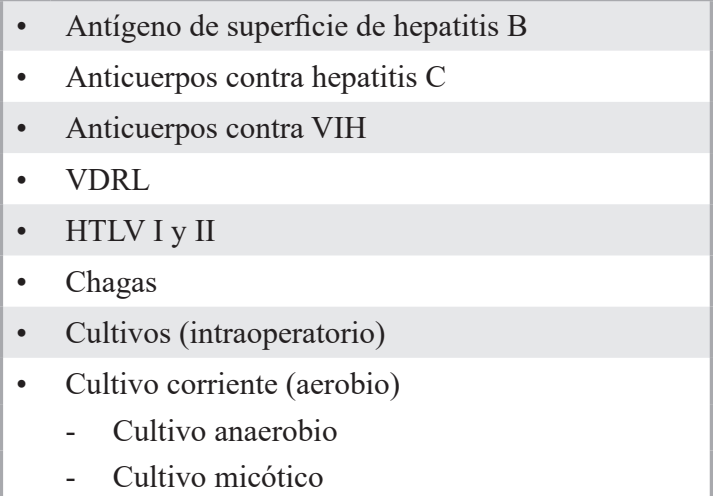

\section{Proceso quirúrgico/abdominoplastía}

La procura de piel se realizó en pabellón, en el mismo tiempo quirúrgico que la abdominoplastía, con todas las medidas de asepsia y antisepsia, bajo anestesia general y por el mismo equipo quirúrgico (anestesista, dos cirujanos plásticos, cirujano de procuramiento, arsenalera, pabellonera, auxiliar de anestesia, enfermera de pabellón y enfermera de procuramiento). Posterior a la marcación de la elipse transversa de piel infraumbilical (Figura 1) y realizada la disección del colgajo cutáneo adiposo abdominal, se realizó la resección del colgajo redundante, para posteriormente en forma simultánea dividir los equipos y por un lado proseguir con la abdominoplastía y en una mesa quirúrgica independiente realizar la procura de la piel.

\section{Procuramiento de piel}

El colgajo cutáneo adiposo resecado en forma de elipse fue colocado en una mesa quirúrgica independiente. Se realizó la procura de piel total (incluyendo dermis), liberando la grasa de la dermis más profunda usando tijeras (Figura 2). Se tomaron, además, muestras de tejido (3) para cultivo corriente (aerobio), cultivo anaerobio y cultivo micótico. La piel procurada se depositó en un recipiente estéril con $500 \mathrm{cc}$ de suero fisiológico con $1 \mathrm{~g}$ de cloxacilina y $80 \mathrm{mg}$ de gentamicina, cerrado de manera hermética cuidando que la piel quedara totalmente sumergida.

\section{Empaque e identificación de la piel}

Los frascos que contenían la piel fueron almacenados en doble bolsa estéril, de al menos 90 micrones. Se cerraron herméticamente cada una de ellas, eliminando la mayor cantidad de aire y se

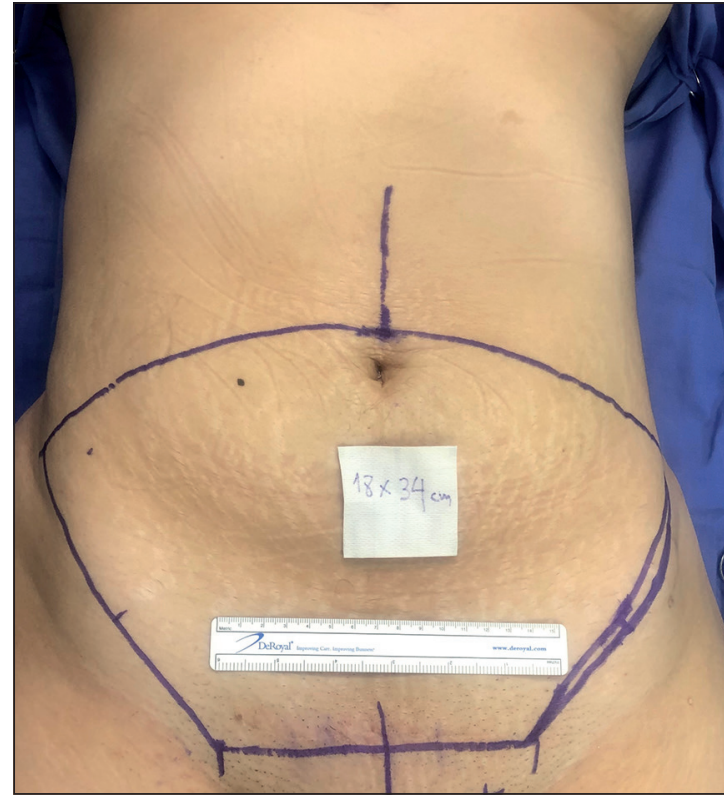

Figura 1. Marcación de colgajo abdominal.

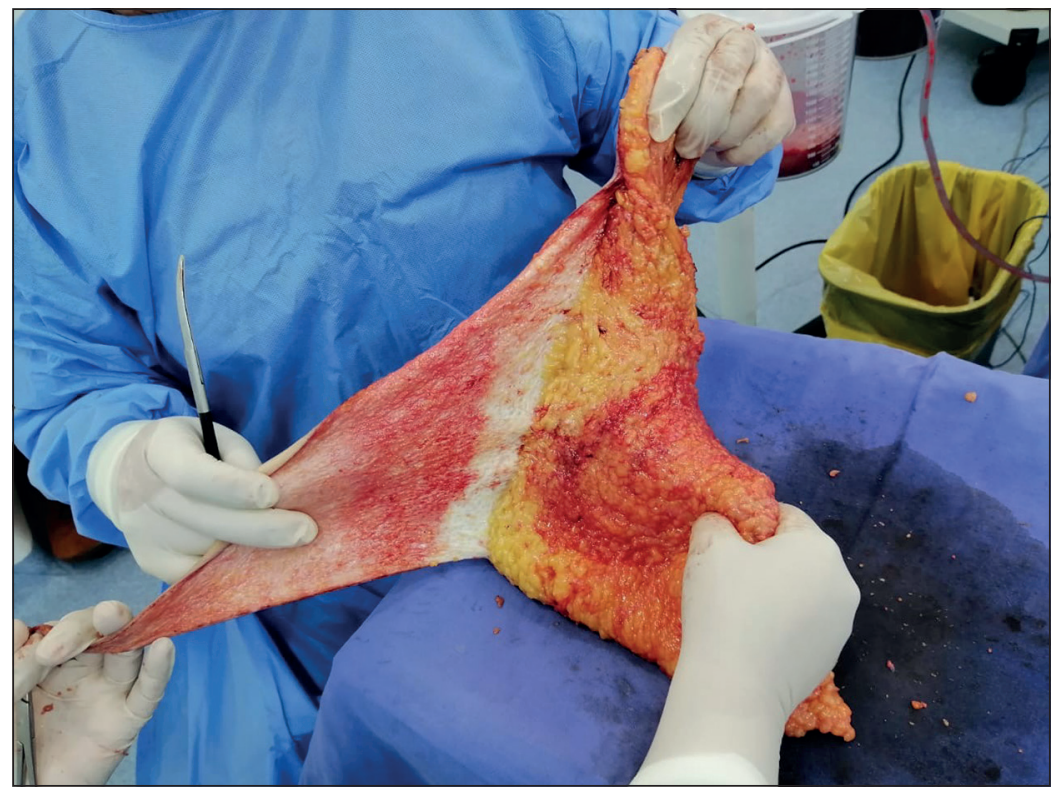

Figura 2. Procura de piel total de colgajo abdominal con tijeras.

rotularon con el código del tejido y la fecha y hora del procuramiento.

\section{Almacenamiento de la piel}

La piel se trasladó desde el pabellón al lugar de almacenamiento transitorio en un cooler con unidades refrigerantes de tal forma de mantener la temperatura entre 2 y $8^{\circ} \mathrm{C}$. 


\section{Transporte de la piel}

La piel fue enviada vía aérea para ser procesada desde Iquique (Hospital Dr. Ernesto Torres Galdames, HETG) al Banco Nacional de Tejidos (BNT) en Santiago siempre antes de $36 \mathrm{~h}$ realizada la procura, asegurándose que el contenedor mantuviera una temperatura entre 2 y $8^{\circ} \mathrm{C}$.

\section{Procesamiento}

Los AC fueron preparados en el BNT, como implantes siguiendo dos etapas: a): medición del colgajo, cortes en segmentos según solicitud, revisión del rasurado, ciclos de lavados para disminuir carga microbiana, toma de muestra número 2 para cultivos (la primera fue intraoperatoria) y sumersión en solución criopreservante por 1 hora; b) preparación, recorte, medición, empaque y etiquetado de cada lámina obtenida. Toma de muestras 3 y 4 (cultivo) durante etapa de empaquetado. Toma de muestra 5 (cultivo) para respaldo.

\section{Criopreservación y cuarentena}

Se utiliza glicerol 10\% como solución criopreservante y crioprotector. El ACPT se mantiene congelado a $-80^{\circ} \mathrm{C}$ a espera de resultados de cultivos seriados hasta su irradiación, obteniendo aloinjertos cutáneos de piel total criopreservados (ACPTC). C) Irradiación: esterilización del lote del tejido con dosis de irradiación entre 25 a $28 \mathrm{kGy}$, en hielo seco para mantención de cadena de frío.

\section{Validación, liberación, registros}

Revisión del proceso de donación, procuramiento y procesamiento del tejido, registros en SIDOT.

\section{Traslado}

Regreso del tejido procesado al centro generador (HETG) en hielo seco para mantención de cadena de frío $\left(-80^{\circ} \mathrm{C}\right)$.

\section{Uso clínico}

Al receptor del tejido, se explicaron los riesgos y beneficios del procedimiento, obteniendo el consentimiento informado para el uso de tejido de origen humano, asegurando la trazabilidad y bio vigilancia a través del formulario de implante de tejidos con los datos del receptor y la cantidad de tejidos utilizados con los códigos que lo identifican y eventuales efectos adversos. Las indicaciones clínicas para su uso fueron: a) preparación de heridas crónicas y complicadas para mejorar el lecho de la herida para un autoinjerto posterior; b) defectos de cobertura sin condiciones para autoinjertos o colgajos locales; c) aparostomías contenidas sin posibilidad de cierre, y d) posterior a resección de melanoma. En el preoperatorio inmediato y calculado el tamaño del defecto a cubrir, el ACPTC se lavó 3 veces con suero fisiológico tibio (no más de $40^{\circ} \mathrm{C}$ ) para eliminar los crioprotectores. Se preparó el lecho receptor mediante la escarectomía de tejidos necróticos, desvitalizados y zonas de granulación desordenada, fijando el ACPT con puntos y/o corchetes asociado a terapia de presión negativa ${ }^{18}$.

\section{Resultados}

La muestra de donantes de piel se compuso de 14 pacientes de sexo femenino, con edades entre los 31 a 55 años y un promedio de edad de 40 años, de las cuales 2 tenían el antecedente de cirugía bariátrica. La superficie cutánea procurada se estimó utilizando la fórmula del área de una elipse (radio mayor $\mathrm{x}$ radio menor $\mathrm{x}$ p), la cual disminuyó posteriormente debido a la contracción primaria de la piel total procurada y a la eliminación de bordes al momento del procesamiento para dejar láminas de múltiples tamaños de utilidad clínica. El promedio de piel y láminas de utilidad clínica procesadas fue de $302 \mathrm{~cm}^{2}$ y 8,3 láminas respectivamente por paciente (Figura 3, Tabla 4) (el lote de tejidos de los últimos 6 pacientes, fueron perdidos debidos al incendio ocurrido en el Hospital Clínico San Borja Arriarán, que afectó al BNT).

La muestra clínica se compuso de 10 pacientes (en dos pacientes se realizaron 2 procedimientos), con edades entre 2 meses a 75 años, con diagnósticos de: pie diabético (4), laparostomía contenida (2) herida compleja extremidad inferior (2), sarcoma de cuero cabelludo recidivado (1) y melanoma

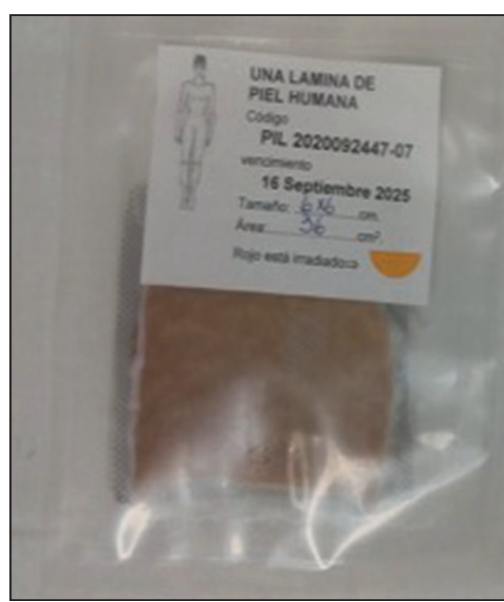

Figura 3. Láminas de utilidad clínica. 
ARTÍCULO ORIGINAL

Tabla 4. Donación y procuramiento de piel

\begin{tabular}{|c|c|c|c|c|c|c|c|}
\hline Paciente & $\begin{array}{l}\text { Edad } \\
\text { (años) }\end{array}$ & $\begin{array}{l}\text { Cirugía ba- } \\
\text { riátrica }\end{array}$ & $\begin{array}{c}\text { Diámetro } \\
\text { mayor }(\mathbf{c m})\end{array}$ & $\begin{array}{l}\text { Diámetro } \\
\text { menor }(\mathbf{c m})\end{array}$ & $\begin{array}{c}\text { Superficie } \\
\text { procurada }\left(\mathrm{cm}^{2}\right)\end{array}$ & $\begin{array}{l}\text { Número de } \\
\text { láminas }\end{array}$ & $\begin{array}{l}\text { Superficie de utilidad } \\
\text { clínica }\left(\mathrm{cm}^{2}\right)\end{array}$ \\
\hline 1 & 32 & No & 37 & 18 & 523 & 8 & 300 \\
\hline 2 & 33 & No & 45 & 18 & 635 & 9 & 385 \\
\hline 3 & 39 & No & 45 & 18 & 635 & 9 & 230 \\
\hline 4 & 39 & No & 51 & 17 & 680 & 6 & 316 \\
\hline 5 & 41 & No & 44 & 16 & 552 & 8 & 300 \\
\hline 7 & 31 & No & 55 & 17 & 654 & 10 & 305 \\
\hline 8 & 42 & No & 49 & 18 & 654 & 9 & 310 \\
\hline 9 & 34 & No & 49 & 18 & 692 & Siniestrada* & Siniestrada* \\
\hline 10 & 34 & No & 45 & 17 & 600 & Siniestrada* & Siniestrada* \\
\hline 11 & 45 & Sí & 55 & 18 & 777 & Siniestrada* & Siniestrada* \\
\hline
\end{tabular}

*Incendio ocurrido en el Hospital Clínico San Borja Arriarán, que afectó al BNT.

Tabla 5. Donación de piel en Chile. 2017-2019

\begin{tabular}{|ccccc|}
\hline Año & $\begin{array}{c}\text { Donantes } \\
\text { totales }\end{array}$ & $\begin{array}{c}\text { Donantes } \\
\text { efectivos }\end{array}$ & $\begin{array}{c}\text { Número de } \\
\text { láminas }\end{array}$ & $\begin{array}{c}\text { Superficie de } \\
\text { utilidad clínica }\end{array}$ \\
\hline 2017 & 1 & 1 & 37 & 3.051 \\
\hline 2018 & 1 & 1 & 14 & 1.069 \\
\hline 2019 & 4 & 2 & 67 & 6.839 \\
\hline
\end{tabular}

(1). En todos los pacientes hubo un prendimiento inicial de $\mathrm{AC}$, que posterior a los 21 días inició el rechazo evidenciado por un cambio de coloración del $\mathrm{AC}$ y la formación de una escara necrótica superficial, que al ser retirada presentaba un tejido vital adherido al receptor, siendo algunos pacientes auto injertados y otros manejados con cicatrización por segunda intención como tratamiento definitivo. La histología del AC presentó al ser retirado focos de necrosis con una infiltración principalmente de polimorfos nucleares y para el caso del lecho receptor una interfase rica en fibroblastos y vasos de neoformación (Figura 4). Esta interfase o neo dermis es visible mediante el estudio de imágenes, en la RNM el ACPTC con un componente superficial no captante y un componente profundo que realza con el medio de contraste, símil a dermis vascularizada $^{19}$. Los resultados de la serie clínica se resumen en la Tabla 6, mostrando algunas imágenes clínicas en las Figuras $6,7,8$. Cabe destacar que producto de la pandemia por SARS-CoV-2, existió un grupo de pacientes a los cuales se perdió el seguimiento.

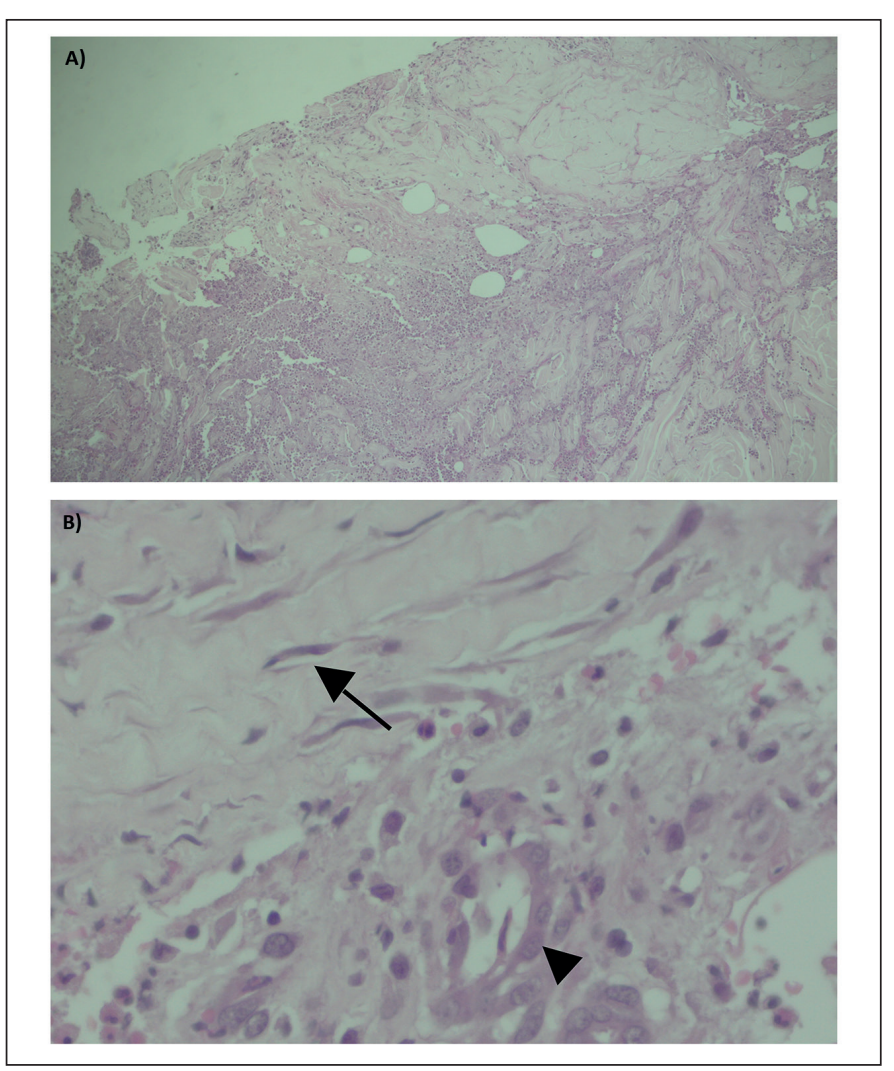

Figura 4. A: Histología. Tinción hematoxilina/eosina. Aumento 2,5x ACPTC al momento de la escarectomía (21 días). Se observa una infiltración de polimorfos nucleares, con zonas de necrosis. B: Lecho receptor pos-ACPTC. Aumento 40x. Flecha negra: fibroblastos, cabeza de flecha: vasos de neoformación. 


\section{ARTíCULO ORIGINAL}

Tabla 6.

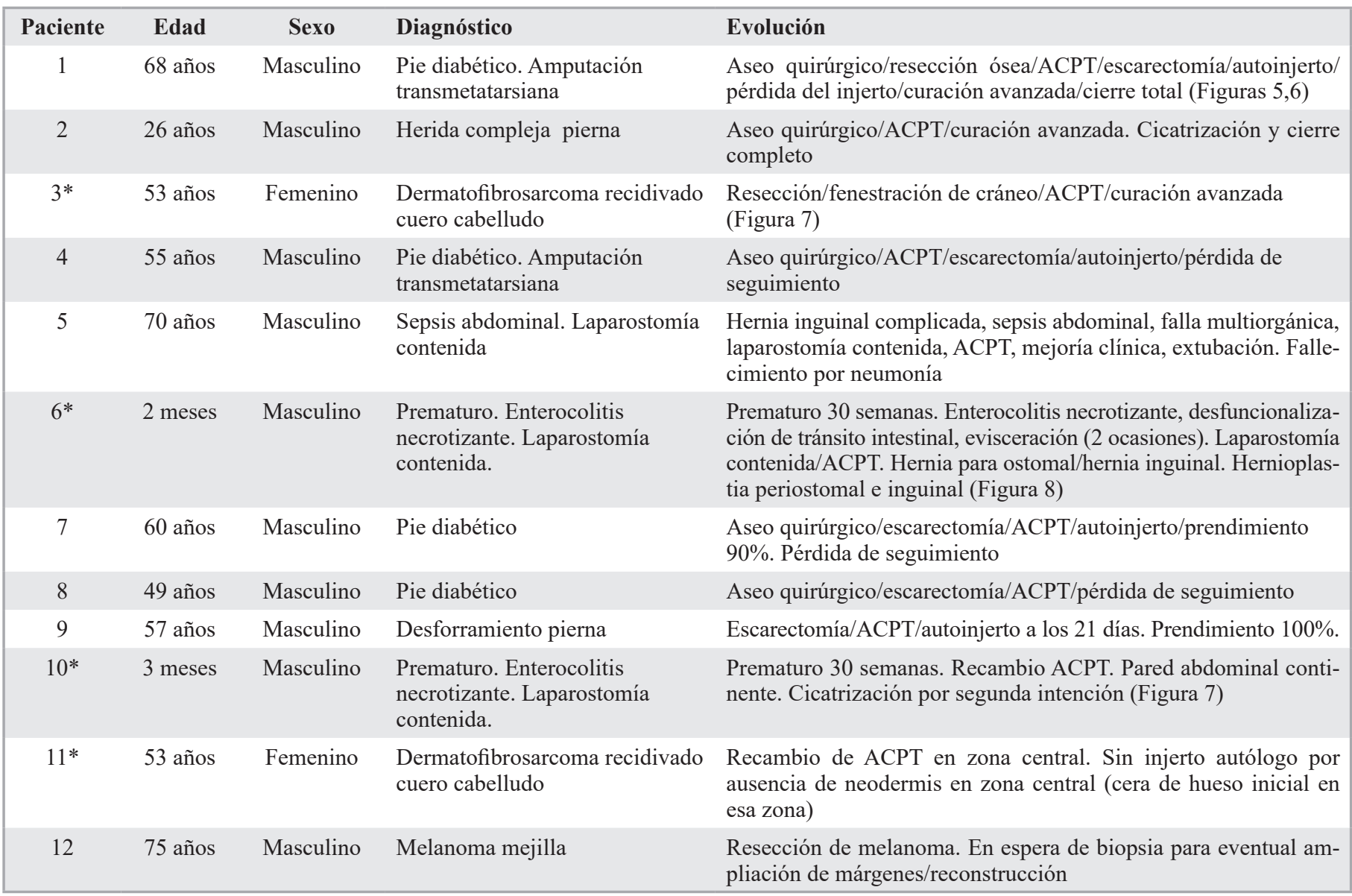

\section{Discusión}

La experiencia clínica presentada reafirma la posibilidad de que las cirugías de contorno corporal se transformen en fuentes de $\mathrm{AC}$, pero en este caso en particular de piel total (ACPT), los cuales al preservarse mediante criopreservación (ACPTC) mantienen su viabilidad y muchos elementos de la dermis donante, en especial los fibroblastos, los cuales se adhieren al receptor, transformándose en una cobertura intermedia para algunos pacientes y definitiva para otros.

En lugares donde la tasa de donación general y particular de piel es baja y en otros en donde su uso todavía no está legalizado principalmente por motivos culturales y religiosos, se abre como opción al uso de $\mathrm{AC}$ proveniente de donante vivo de pacientes sometidas a procedimientos de contorno corporal, en este caso particular a una abdominoplastía ${ }^{20,21}$. El número de donantes efectivos de piel en Chile en el trienio 2017-2019 fue de sólo cuatro donantes, obteniendo $3.051 \mathrm{~cm}^{2}, 1.069 \mathrm{~cm}^{2}$ y $6.839 \mathrm{~cm}^{2}$ de piel por año respectivamente (todos donantes cadavéricos). En nuestra experiencia, por cada abdominoplastía se obtienen aproximadamente $302 \mathrm{~cm}^{2}$ de piel procesada de utilidad clínica, lo cual nos refleja el potencial de este procedimiento como fuente importante de AC y ACPTC (Tabla 5).

Los AC, ocupan un lugar preponderante dentro de las técnicas de cobertura temporal sobre todo en los pacientes quemados con escaso capital cutáneo residual, proporcionando un revestimiento fisiológico que permite controlar las pérdidas hidroelectrolíticas, disminuir el dolor, reducir el riesgo de infección y mejorar las condiciones locales del lecho, promoviendo la angiogénesis y maduración 


\section{ARTíCULO ORIGINAL}
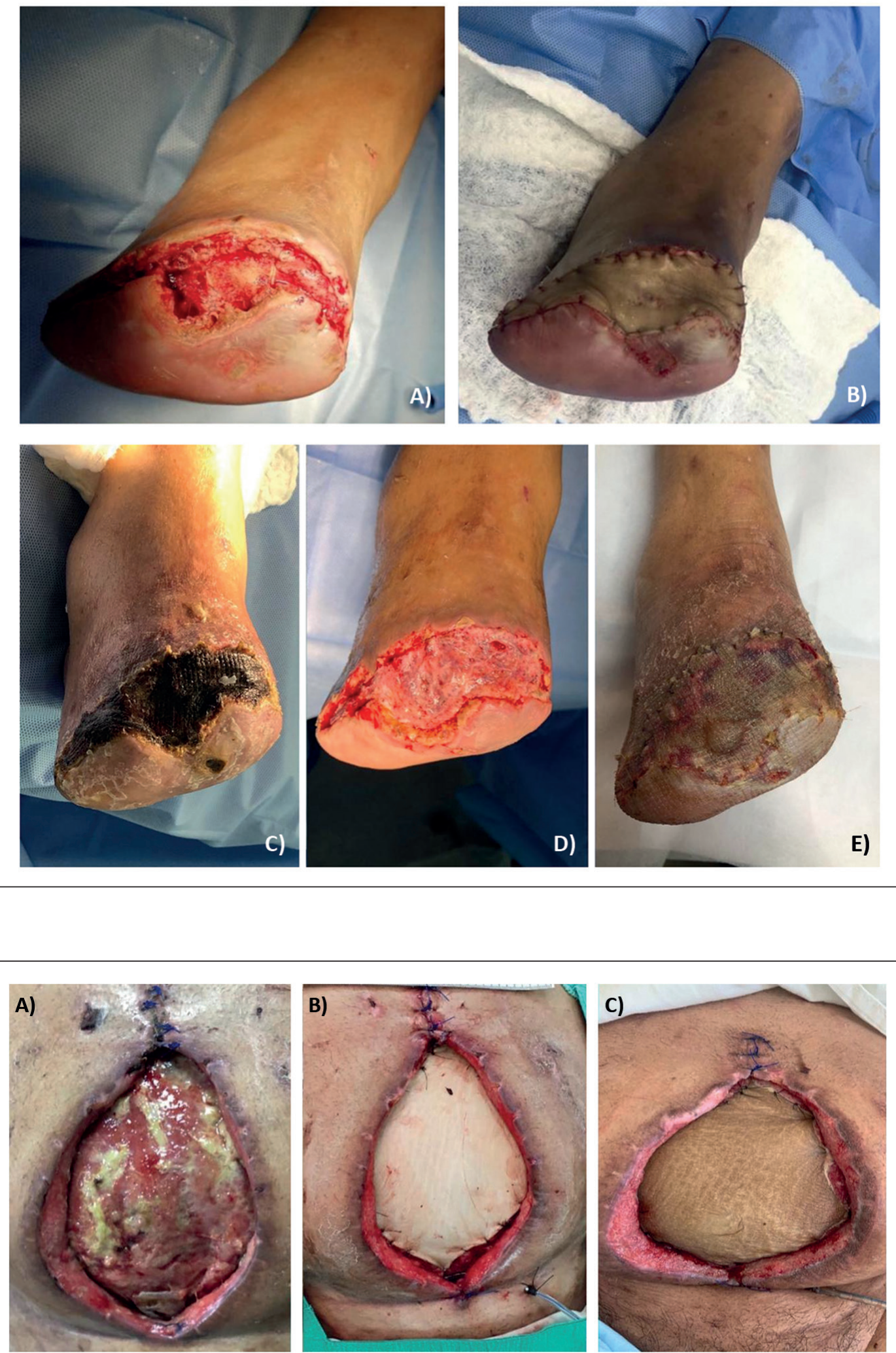

Figura 5. Paciente de 56 años, con antecedentes de diabetes mellitus 2 y enfermedad arterial oclusiva de extremidades inferiores bilateral y amputación infracondílea izquierda; con necrosis de colgajo posterior a amputación transmetarsiana derecha. A: déficit cobertura con exposición ósea y cobertura con tejido granulatorio desordenado. B: Cobertura con ACPTC. C: Evolución ACPT 28 días. D: Lecho receptor posescarectomía de parte superficial de ACPTC, se observa la neodermis; E: Autoinjerto piel parcial, resultado al día 7.

Figura 6. Paciente de 70 años, con antecedentes de sepsis abdominal, secundaria a hernia inguinal perforada. Con estadía prolongada en unidad de cuidados intensivos y ventilación mecánica. Múltiples aseos quirúrgicos, eviscerado en 2 ocasiones posterior a intentos de cierre de pared abdominal. A: Abdomen abierto. B: Cobertura con ACPTC, posterior a lo cual el paciente presenta una mejoría clínica y sale de ventilación mecánica. C: Resultado a los 14 días (el paciente evoluciona con una neumonía falleciendo). 


\section{ARTÍCULO ORIGINAL}
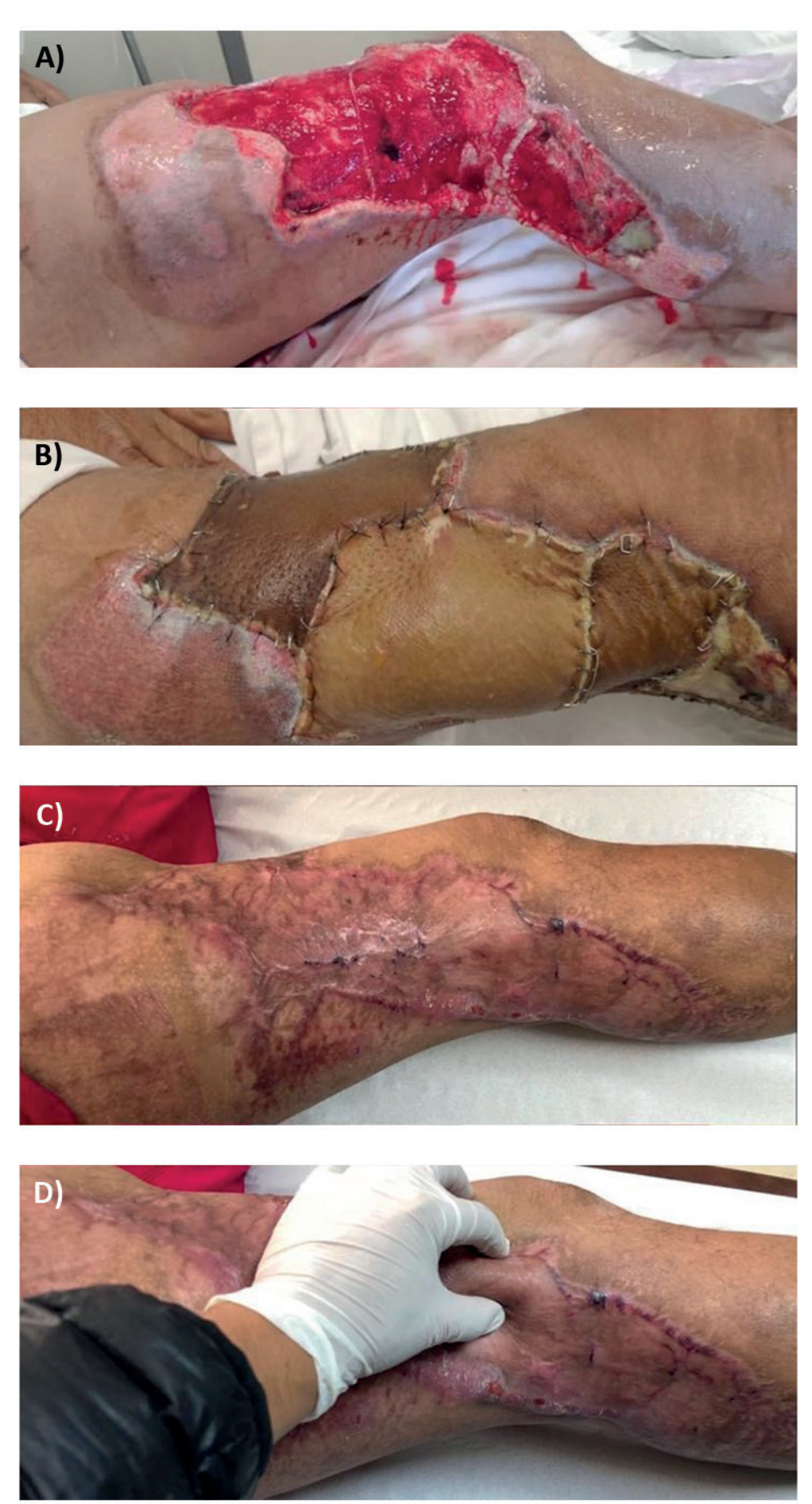

Figura 7. A: Desforramiento de pierna derecha. B: 14 días de posoperatorio de cobertura con aloinjerto cutáneo de piel total criopreservado (ACPTC). Nótese la diferencia de color de los distintos segmentos al ser de distintos donantes y el rechazo inicial mayor en la región distal. C: Resultado posautoinjerto cutáneo. d. Prueba del pliegue para evaluar el grosor y elasticidad resultante. del tejido de granulación subyacente, existiendo una extensa experiencia en el uso clínico de los mismos, pero la mayoría provenientes de donante cadavérico, es decir, de piel parcial y escasas experiencias en ACPT no encontrando ninguna con ACPTC viables, entendiendo la viabilidad como la capacidad de una unidad biológica de permanecer viva, la cual está directamente relacionada con el mecanismo de preservación $^{22-28}$. La preservación mediante glicerol a altas concentraciones es el método predominante de la mayoría de los bancos de tejidos, pues es de fácil realización, pero resultando en tejidos no viables ${ }^{29,30}$. Por otra parte, la criopreservación, congela los AC en presencia de un crioprotector, el cual previene los efectos de la cristalización manteniendo la viabilidad en el tiempo tras la congelación. El porcentaje de prendimiento está directamente relacionado con la viabilidad y la arquitectura de los tejidos, siendo mayor cuando los tejidos son viables ${ }^{31}$.

Para los AC, ya se había descrito que algunos elementos de la dermis, principalmente los fibroblastos, se podían integrar en forma definitiva en el receptor, describiéndose en la literatura, situaciones excepcionales de prendimiento completo y ausencia de rechazo del AC, siendo el caso más mediático el que involucró a Sir Winston Churchill, quien durante la Guerra del Nilo, donó piel y fue injertada a un compañero herido y permanece allí hasta el día de hoy y la hizo durar bien de muchas maneras. Yo, por mi parte, guardo la cicatriz como recuerdo" 32,33 . Los ACPTC utilizados en este estudio mantienen toda la dermis del donante, la cual participa en la formación de una neo dermis rica en fibroblastos y vasos de neoformación, actuando además como un andamiaje e inductor biológico para el lecho receptor (Figura 4b). Se ha comprobado en modelos de xenoinjerto que los ACPTC promueven la angiogénesis y la producción de colágeno tipo 1 sin provocar una respuesta fibrótica significativa ${ }^{34}$.

Para los AC el rechazo es la evolución natural $\mathrm{y}$ en individuos sanos esto se produce entre los 8 a 10 días, pudiendo retrasarse en grandes quemados, producto de la depresión del sistema inmune, entre 15 a 30 días. En nuestra experiencia con ACPTC, el rechazo es más tardío, siendo clínicamente evidente a partir de la tercera semana, caracterizándose por una infiltración de polimorfos nucleares en la epidermis. El rechazo del ACPTC no debe interpretarse como fracaso terapéutico, sino una etapa de lo que hemos denominado cobertura intermedia, pues parte del ACPTC se pierde y parte se adhiere al lecho receptor, obteniendo una interfase de "neodermis", lo cual permite por un lado completar la cobertura definitiva con un autoinjerto o por otra parte completar 
la cicatrización por segunda intención, en donde, además, se produce una contracción secundaria de la herida que disminuye el tamaño del defecto. De esta forma los ACPTC pueden ser utilizados como una alternativa al uso de matrices dérmicas, en donde además de la cobertura de estructuras como hueso, cartílago y tendones se obtiene un revestimiento de mejor calidad, con mayor grosor y elasticidad ${ }^{35}$.

Los usos terapéuticos del ACPTC pueden ser múltiples, destacando en nuestra serie el pie diabético, déficit de coberturas extensos y complejos, laparostomías contenidas y posterior a resección de tumores cutáneos, en espera de biopsias para eventual ampliación de márgenes y reconstrucción ${ }^{36-41}$.

\section{Conclusión}

La procura de piel total en donante vivo, en pacientes sometidos a cirugías de contorno corporal es un proceso factible, fuente de ACPTC, que al ser criopreservados se obtienen tejidos viables, los cuales dan inicio a un nuevo tipo de cobertura, que hemos denominado cobertura intermedia, de fácil uso y con múltiples aplicaciones clínicas.

\section{Responsabilidades éticas}

Protección de personas y animales. Los autores declaran que para esta investigación no se han realizado experimentos en seres humanos ni en animales.

Confidencialidad de los datos. Los autores declaran que en este artículo no aparecen datos de pacientes.

Conflictos de interés: no hay.

El presente estudio se realizó bajo la supervisión de la Coordinación Nacional de Procuramiento y Trasplante de Órganos y Tejidos (CNPT) del Ministerio de Salud de Chile.

\section{Bibliografía}

1. Vig K, Chaudhari A, Tripathi S, Dixit S, Sahu R. Pillai, S, et al. Advances in skin regeneration using tissue engineering. Int J Mol Sci. 2017;18:789. doi: 10.3390/ ijms 18040789 .

2. Hallock G, Morris S. Skin grafts and local flaps. Plast Reconstr Surg. 2011;127:5e-22e.

3. Revol M, Servant JM. Injertos cutáneos. EMC-Cirugía Plástica Reparadora y Estética 2010;18:1-11.

4. Lakhel A, Pradier JP, Brachet M, Duhoux A, Duhamel P, et al. Cirugía de las quemaduras graves en la fase aguda. EMC-Cirugía Plástica Reparadora y Estética 2008;16:1-39.

5. Miller TA, Switzer WE, Foley FD Moncrief JA. Early homografting of second degree burns. Plast Reconstr Surg. 1967;40:117-25.

6. Burd A, Chiu T. Allogenic skin in the treatment of burns. Clin Dermatol 2005;23: 376-87.

7. Gaucher S, Jarraya M. Aloinjertos cutáneos en la cirugía del gran quemado. EMC-Cirugía Plástica Reparadora y Estética 2009;17:1-10.

8. Dantzer E. Indicaciones de los sustitutos cutáneos y de los aloinjertos. EMC-
Cirugía Plástica Reparadora y Estética 2015;23:1-14

9. Rosenberg S, Singer A. Cellular basis of skin allograft rejection: an in vivo model of immune-mediated tissue destruction. Annu Rev Immunol. 1992;10:333-60.

10. Lazzeri D, Pantaloni M, Agostini T. Homografts and the Rejection Phenomenon: from burn care to organ transplantation. Plast Reconstr Surg. 2010;126:1802-3.

11. González F, Vera F, Alcayaga R, González F. Análisis crítico de la baja tasa de donación de órganos en Chile. Rev Med Chile 2020;148:242-51.

12. Zúñiga-Fajuri A, Merino M, Urtubia M. Una mirada al origen, funcionamiento y desafíos del nuevo sistema de donación y trasplantes chileno. Rev Med Chile 2018;146:780-5.

13. Ministerio de Salud. Gobierno de Chile. Norma general técnica para el procuramiento, preservación e implante de tejidos. 2018.

14. Gaucher S, Khaznadar Z, Gourevitch JC, Jarraya M. Skin donors and human skin allografts: evaluation of an 11year practice and discard in a referral tissue bank. Cell and Tissue Banking 2015;17:11-19.
15. Chua A, Song C, Chai A, Chan L, Tan $\mathrm{K}$. The impact of skin banking and the use of its cadaveric skin allografts for severe burn victims in Singapore. Burns 2004;30:696-700.

16. Friedland J, Maffi T. MOC-PS (SM) CME Article: Abdominoplasty. Plast Reconstr Surg 2008;121:1-11.

17. Thirumalai A, Varma S. Geometric incision designing for abdominoplasty. Plast Reconstr Surg. 2002;109:2534-6.

18. Gupta S. Optimal use of negative pressure wound therapy for skin grafts. International wound journal 2012;9:40-7.

19. Stefanowska J, Zakowiecki D, Cal K. Magnetic resonance imaging of the skin. Journal of the European Academy of Dermatology and Venereology 2010;24:875-80

20. Vera M, Alegría L, Domínguez J, Rebolledo R, Dib M. Donación y trasplante de órganos: análisis y propuestas para avanzar hacia una cultura de donación. Temas de la Agenda Pública 2019;14:1-20. Centro de Políticas Públicas UC.

21. Zidan S, Eleowa S. Banking and use of glycerol preserved full-thickness skin allograft harvested from body contouring procedures. Burns 2014;40:641-7.

22. Khoo TL, Halim AS, Saad AM, Dorai AA 


\section{ARTÍ́CULO ORIGINAL}

The application of glycerol-preserved skin allograft in the treatment of burn injuries: an analysis based on indications. Burns 2010;36:897-904

23. Pegg DE. Viability assays for preserved cells, tissues, and organs. Cryobiology 1989;26:212-31.

24. Alexander J, Mac Millan B, Law E, Kittur D. Treatment of severe burns with widely mesh skinautograft and Meshed skin allograft overlay. J Trauma 1981;21:4338.

25. Leon-Villapalos J, Eldardiri M,

Dziewulski P. The use of human deceased donor skin allograft in burn care. Cell tissue bank 2010;11:99-104.

26. Steenvoorde MD. Use of cadaveric donor skin to predict success of a definitive split-thickness skin graft in complicated wounds. Wounds 2010;22:284-8.

27. Cuono C, Langdon R, Birchall N, Barttelbort S, McGuire J. Composite autologous-allogenic skin replacement: development and clinical application. Plast Reconstr Surg. 1987;80:626-35.

28. Rooney P, Eagle, M, Hogg P, Lomas R, Kearney J. Sterilisation of skin allograft with gamma irradiation. Burns 2008;34:664-73.

29. Messager S, Hann AC, Goddard PA, Dettmar PW, Maillard JY. Assessment of skin viability: is it necessary to use different methodologies? Skin Res Technol 2003;9:321-30.

30. de Backere AC. Euro Skin Bank: large scale skin-banking in Europe based on glycerol-preservation of donor skin. Burns 1994;20(suppl 1):S4-S9.

31. Castagnoli C, Alotto D, Cambieri I, Casimiri R, Aluffi M, Stella M, et al. Evaluation of donor skin viability: fresh and cryopreserved skin using tetrazolioum salt assay. Burns 2003;29:759-67.

32. Pomahac B, Garcia J, Lazar A, Tilney N, Orgill D. The skin allograft revisited: A potentially permanent wound coverage option in the critically ill patient. Plast Reconstr Surg 2009;123;1755-8.

33. Knobloch K, Vogt P. Allograft skin as a permanent tissue repair: to mesh or not? Plast Reconstr Surg. 2010;125:750-1.

34. Henn D, Chen K, Maan Z, Greco A, Moortgat Illouz S, Bonham C, et al. Cryopreserved human skin allografts promote angiogenesis and dermal regeneration in a murine model. International Wound Journal 2020;17:92536.

35. Lee LF, Porch JV, Spenler W, Garner WL. Integra in lower extremity reconstruction after burn injury. Plast Reconstr Surg. 2008;121:1256-62.

36. Bejarano P, Levi D, Nassiri M, Vincek V, García M, Weppler D, et al. The pathology of full-thickness cadaver skin transplant for large abdominal defects: a proposed grading system for skin allograft acute rejection. The American journal of surgical pathology 2004;28;670-5.

37. Michielin O, Van Akkooi A, Ascierto P, Dummer R, Keilholz U. Cutaneous melanoma: ESMO Clinical Practice Guidelines for diagnosis, treatment and follow-up. Annals of Oncology 2019;30:1884-901.

38. Seguel G. ¿Por qué debemos preocuparnos del pie diabético?: Importancia del pie diabético. Rev Med Chile 2013;141:14649.

39. Di Domenico L, Emch K, Landsman A, Landsman A. A Prospective Comparison of Diabetic Foot Ulcers Treated With Either a Cryopreserved Skin Allograft or a Bioengineered Skin Substitute. Wounds 2011;23:184-9.

40. Álvaro-Afonso F, García-Álvarez Y, Lázaro-Martínez J, Kakagia D, Papanas N. Advances in dermoepidermal skin substitutes for diabetic foot ulcers. Current vascular pharmacology 2020;18:182-92.

41. Gordon A, Alfonso A, Nicholson J, Chiu E. Evidence for healing diabetic foot ulcers with biologic skin substitutes: a systematic review and meta-analysis. Annals of plastic surgery 2019;83(4S):S31-S44. 